\title{
Evaluation of selected properties of coatings in respect of risk elimination of surface damage of stamped parts
}

\author{
Tkáčová J. ${ }^{1}$, Zdravecká E. ${ }^{1}$, Evin E. ${ }^{1}$, Tomáš $M .^{1}$, Jakubéczyová D. ${ }^{2}$ \\ 1 Technická Univerzita v Košiciach \\ ${ }^{2}$ Ústav materiálového výskumu SAV, Košice \\ E-mail: jana.tkacova@tuke.sk
}

For achieving a long service life of stamping dies for new types of steel sheets intended for the automotive industry, the tribosystem must be optimally designed. One of the possible solutions is its optimization by coatings. More modern coating technologies for stamping dies include PVD (physical vapor deposition) and CVD (chemical vapor deposition) methods. The properties of PVD TiCN and DLC (diamond-like carbon) coatings deposited on ledeburitic high-alloy $\mathrm{Cr}-\mathrm{Mo}-\mathrm{V}$ steel were analyzed by standard tests (coating adhesion by both the scratch and Rockwell C tests, microhardness by Vickers method and coating thickness by Calotest) and developed tribometer of the "friction jaw-roller" type at drawing double-sided hot-dip galvanized steel sheet. The obtained results showed better tribological behavior of the DLC coating.

\section{INTRODUCTION}

In the case of sheet metal stamping dies, it is an effort to apply thin coatings to increase the die lifetime and also to improve the stamping process $[1,2]$. The coating, as a contact layer on the stamping die, is applied to provide the resistance to oxidation, abrasion, and wear [3]. The coatings for the deep drawing dies are subjected to problems of complex wear, fatigue, and lubrication, in addition to thermal exposure (up to $400{ }^{\circ} \mathrm{C}$ ). More modern coating methods for thin films include physical and chemical deposition techniques (PVD, CVD). PVD coating technique includes a wide range of materials such as metals, alloys, and ceramics that can be applied to most materials with a wide range of shapes. Examples of PVD coatings are $\mathrm{CrN}$, TiN, TiCN, DLC, etc. [4-8].

The wear of the stamping dies occurs due to slipping movement and usually is connected with adhesion, abrasion, transfer phenomena as well as micro-cracks of the brittle surface; such damage deteriorates the quality of the stampings. The properties of coatings (such as layer thickness, hardness, friction coefficient, adhesion, cohesion, wear resistance) can be evaluated by various experimental methods [9]. Over the years, many standard and modified tests were applied to evaluate tool materials and coatings in sheet metal stamping processes.
The basic requirement for laboratory tests is to model the real conditions of tribosystem (load, temperature, environments, etc.). The coating/substrate interface is the weakest link that needs to be studied in connection with the system's adhesive properties. Scratch test and Rockwell C indentation test are frequently used to study the adhesion of coating/substrate systems.

The coefficient of friction is an important input parameter in sheet metal stamping simulations. The good adhesion of the coating prevents it from peeling off, delamination or tearing off under frictional forces. The friction coefficient varies during the stamping process, and frictional behavior depends on many parameters (e.g. velocity, load, material, etc.). The friction coefficient and wear resistance (adhesion, abrasion, ...) can be identified by various tribometers i.e. with the point, line, and surface contact e.g., pin-on-disc or modified cup drawing tests (strip drawing test, limiting dome height test, stamping lubricant tester). There are more experimental settings for strip-drawing testers, including cylindrical beads, rollers, and flat jaws [10-14].

DLC coatings represents an attractive group of materials with high hardness, high abrasion protection, low friction losses, high sliding speeds, even without lubrication $[15,16]$.

TiCN coating is suitable for cold forming applications of steel and other non ferrous alloys and shows effectiveness in reducing galling in forming galvanize advance high strength steel $[17,18]$. TiCN coatings are known for their self-lubricating properties [19].

This contribution deals with evaluation of the properties of PVD TiCN and DLC (diamond-like carbon) coatings deposited on ledeburitic high-alloy $\mathrm{Cr}-\mathrm{Mo}-\mathrm{V}$ steel by standard tests (coating adhesion by both the scratch and Rockwell $\mathrm{C}$ tests, microhardness by Vickers method and coating thickness by Calotest) and originally designed tribometer of the "friction jaw-roller" type at drawing double-sided hot-dip galvanized steel sheet. Designed tribometer allows investigating the behavior of the drawn strip under different loads, different lubrication modes, and stress conditions. 


\section{EXPERIMENTAL}

\section{Materials}

Friction tests were carried out on hot-dip galvanized steel sheet $\mathrm{H} 220 \mathrm{PD}+\mathrm{Z100MBO}$ with dimensions of $50 \times 1700 \times 0.8 \mathrm{~mm}$. It is micro-alloyed steel with a higher strength determined for cold stamping. The mechanical properties determined in a uniaxial tensile test according to the EN ISO 6892-1: 2016 by tensile machine TIRATEST 2300 were as follows: the yield strength of $\mathrm{R}_{\mathrm{p} 0.2}=223 \mathrm{MPa}$, the tensile strength of $\mathrm{R}_{\mathrm{m}}=368 \mathrm{MPa}$, ductility $\mathrm{A}_{80}=38 \%$. A zinc coating of $100 \mathrm{~g} \mathrm{~m}^{-2}$ on both sides corresponds to $7 \mu \mathrm{m}$ coating on each side.

Lubricant Anticorit Prelube 3802-39S was used in the experiments. It is a barium-free, thixotropic lubricating oil preventing corrosion, suitable for deep drawing of steel sheets (conventional steel sheets, galvanized sheets, sheets with or without phosphate layer) to ensure their optimum performance for demanding applications. Viscosity at $40{ }^{\circ} \mathrm{C}$ is $60 \mathrm{~mm}^{2} \mathrm{~s}^{-1}$, density at $15^{\circ} \mathrm{C}$ is $910 \mathrm{~kg} \mathrm{~m}^{-3}$, flash point is $180^{\circ} \mathrm{C}$. Sheets coated with prelubes prior to dispatch from steel mills can undergo difficult pressing operations without additional lubrication [20].

In the presented work, two types of PVD coatings, TiCN and DLC, deposited on ledeburitic high-alloy $\mathrm{Cr}-\mathrm{Mo}-\mathrm{V}$ steel, were compared. Multi-layered PVD- TiCN coating was deposited by the reactive arc evaporation method. The PVD-DLC coating was deposited by the sputtering method.

The jaws and roller of friction testing equipment used in the experiments were made of 1.2379 steel (EN 1.2379, X153CrMoV12). It is high-alloyed ledeburitic $\mathrm{Cr}-\mathrm{Mo}-\mathrm{V}$ steel, the strength ranges from 750 to $800 \mathrm{MPa}$, the hardness after soft annealing is max. $250 \mathrm{HB}$ and hardness after quenching reaches $63 \mathrm{HRC}$. The functional parts of testing equipment (jaws and roller) were made as follows: (i) uncoated, (ii) PVD$-\mathrm{TiCN}$ coated, and (iii) PVD-DLC coated.

\section{Methodology}

The thickness of coatings was determined by Calotest. The HV 0.1 microhardness of the PVD coated jaws was measured by microindentation hardness tester LECO LM 700 AT at a load of $100 \mathrm{~g}$. Evaluation of coating adhesion was carried out by the Rockwell $\mathrm{C}$ indentation and the scratch test [6, 21-23].

The Rockwell C indentation test was carried out on both (top and bottom) friction simulator jaws coated with PVD TiCN and DLC coatings. The quality of the coating was evaluated according to the resulting imprint produced by the $\mathrm{C}$ diamond conical indenter at a load of $1500 \mathrm{~N}$ by an optical microscope with a focus on the peripheral geometry. The coating evaluation was performed according to the scale expressed in HF1 HF6 degrees (Tab. 1).

The scratch test was performed on the coated jaws in the longitudinal and transverse directions under standard conditions (constantly increasing normal force Fn from 0 to $100 \mathrm{~N}$, speed of the jaw $v=0.1 \mathrm{~mm} \mathrm{~s}^{-1}$, the jaw path of $s=5 \mathrm{~mm}$ ). Acoustic emission AE and coefficient of friction $\mathrm{COF}$ in dependance to the normal force Fn were recorded, and also the surface morphology of coatings TiCN and DLC was observed after test. Based on the knowledge of the load rate and sample feed rate and the

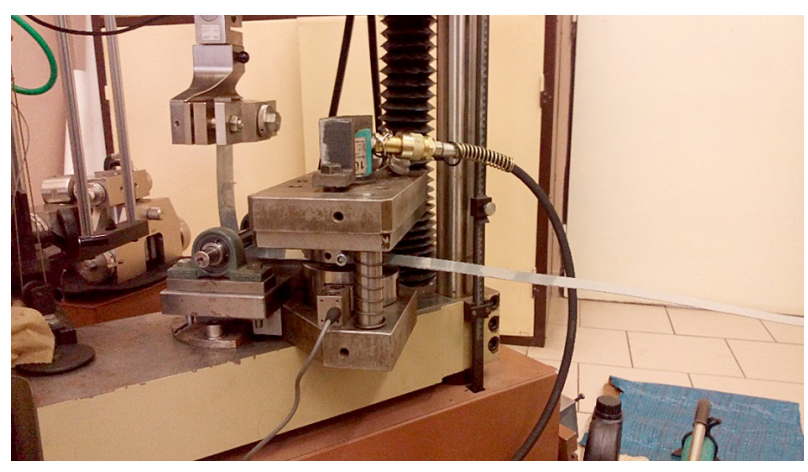

Fig. 1. Friction simulator

Tab. 1. Assessment of adhesion by the Rockwell C indentation

\begin{tabular}{|l|l|l|l|}
\hline \multicolumn{3}{|c|}{ Evaluation of coating adhesion by the Rockwell C indentation test } \\
\hline $\mathrm{HF} 1$ - good adhesion, a small amount of cracks & $\mathrm{HF}$ - reduced adhesion, peeling around \\
the edge of the indent
\end{tabular}


dependence of the acoustic emission signal (AE) values on the magnitude of the normal load Fn on the indentor, the magnitude of the critical load Fc is determined. The scratch test output is a graphical representation of the coating failure process. The scratch test was carried out on a Bruker UNT TriboLab. The surface of the jaw after a scratch test was evaluated by SENSOFAR PLU NEOX optical 3D surface profiler.

The friction coefficient was determined by the originally designed friction simulator, which allows simulating the deep-drawing process - Fig. 1 [24,25]. This modified friction simulator of the "friction jawsroller" type (designed for TIRATEST 2300 tensile machine) enables to model load of contact surfaces in two modes:

- under blank holder using a simulator with rotating roller $\left(f_{3}=0\right)$;

- also on the die drawing edge by using simulator with fixed roller $\left(f_{3}>0\right)$, where $f_{3}$ is friction coefficient on the drawing edge.

The jaws of friction simulator were uncoated and coated with TiCN and DLC coatings. The sheet metal strips were drawn between the simulator jaws at a constant speed $v=25 \mathrm{~mm} \mathrm{~min}^{-1}$. The contact surface is determined by the width and length of the functional surfaces of the jaws. The blank holding force was: $F_{p}=2 \mathrm{kN}, 4 \mathrm{kN}, 6 \mathrm{kN}$, and $8 \mathrm{kN}$. The path of sliding was: $\mathrm{s}=50 \mathrm{~mm}$. During experiments, the drawing force was in the range of $1-10 \mathrm{kN}$ depending on the jaws used, the lubricant and the blank holding force. The surface of drawn strip was lubricated with lubricant Anticorit Prelube 3802-39S. The roughness of top and bottom jaws and roller was $R_{a}=0.4 \mu \mathrm{m}$. After the tests, microscopic and macroscopic analyses were carried out on the drawn strips and jaw surfaces. The surface of the jaws and the drawn strip were monitored using a Plugable USB2-Micro-200X USB digital microscope attached to a computer assembly and Olympus GX71 light metallographic microscope.

In the strip drawing test, the friction coefficient is calculated conventionally by equation 1 , considering friction between strip (top jaw) and the strip (bottom jaw) of the same value:

$$
f_{1}=\frac{F_{t}}{2 \cdot F_{p}}
$$

where: $f_{1}$ - coefficient of friction, $F_{t}-$ drawing force $[\mathrm{N}]$, $F_{p}$ - blank holding force $[\mathrm{N}]$.

The calculation of the coefficient of friction, according to equation (1), does not take into account the bending of the strip at the die drawing edge. For this reason, this method of determining the coefficient of friction is not accurate, and it was necessary to introduce the bending force of the strip.
In the modified friction simulator used, the die drawing edge is replaced by a roller that can rotate and also be blocked. If the roller is blocked, friction is modeled on the die drawing edge. If the roller rotates, the friction is simulated among the die, strip, and the blank holder. These states can be described by equilibrium conditions as follows:

If the roller is braked (friction model on the die drawing edge), the drawing force $F_{t}$ can be determined as follows:

$$
F_{t(f>0)}=\mathrm{e}^{\vartheta \cdot f_{3}} \cdot T+F_{o}
$$

where: $\vartheta$ - angle of wrap, $f_{3}$ - coefficient of friction on the drawing edge of roller, $T$ - friction force on contact surface $[\mathrm{N}], F_{o}$ - bending force on die drawing edge [N].

If the roller rotates (friction model under the blankholder), the friction coefficient on the roller is $f_{3} \approx 0$, and we get the equation:

$$
F_{t(f=0)}=\mathrm{e}^{9 \cdot f_{3}} \cdot T+F_{o}=T+F_{o}
$$

The resulting friction coefficient on the die drawing edge and between the jaws can be determined from the difference in the drawing forces at different blank holding forces $(2 \mathrm{kN}, 4 \mathrm{kN}, 6 \mathrm{kN}, 8 \mathrm{kN})$ in relation to the reference force of $2 \mathrm{kN}$ generated by the braked roller $F_{t(f>0)}$ and the frictional force at the rotating roller $F_{t(f=0) \text {. }}$

$$
\begin{array}{r}
F_{t=2 \mathrm{kN}}=\mathrm{e}^{\vartheta \cdot f_{3}} \cdot T+F_{o} \\
F_{t i}-F_{t=2 \mathrm{kN}}=2 \mathrm{e}^{\vartheta \cdot f_{3}} \cdot f_{2} \cdot F_{p i}+ \\
+F_{o}-2 \mathrm{e}^{\vartheta \cdot f_{3}} \cdot f_{2} \cdot F_{p=2 \mathrm{kN}}-F_{o}
\end{array}
$$

where: $f_{2}$ is coefficient of friction between sheet metal strip and upper and lower jaws.

After arrangement of equation (5) we receive:

$$
f_{2}=\frac{F_{t i}-F_{t=2 \mathrm{kN}}}{2 \cdot e^{\vartheta \cdot f_{3}}\left(F_{p i}-F_{p=2 \mathrm{kN}}\right)}
$$

Assuming the friction coefficient on the drawing edge of the roller $f_{3} \approx 0$, the equation (6) after arrangement will be:

$$
f_{2}=\frac{F_{t i}-F_{t=2 \mathrm{kN}}}{2 \cdot\left(F_{p i}-F_{p=2 \mathrm{kN}}\right)}
$$

The value of the friction coefficient $f_{3}$ on the drawing edge of roller (the friction in bearings is so small, that it can be neglected) can be calculated after substitution the value for $f_{2}$ and the wrapping angle $\vartheta=90^{\circ}$ according to the following modified equation:

$$
f_{3}=\ln \left(\frac{F_{t i}-F_{t=2 \mathrm{kN}}}{2 \cdot f_{2} \cdot\left(F_{p i}-F_{p=2 \mathrm{kN}}\right)}\right) \cdot \frac{2}{\pi}
$$

The friction coefficient for the individual loads was calculated using the Excel software based on the measured and recorded both the drawing and blank holding forces. 


\section{RESULTS AND DISCUSSION}

The thickness of the TiCN coating measured by the Calotest ball-crater test was $3 \mu \mathrm{m} \pm 0.7$. The thickness of the DLC coating measured by the Calotest was $2.5 \mu \mathrm{m} \pm 0.5$.

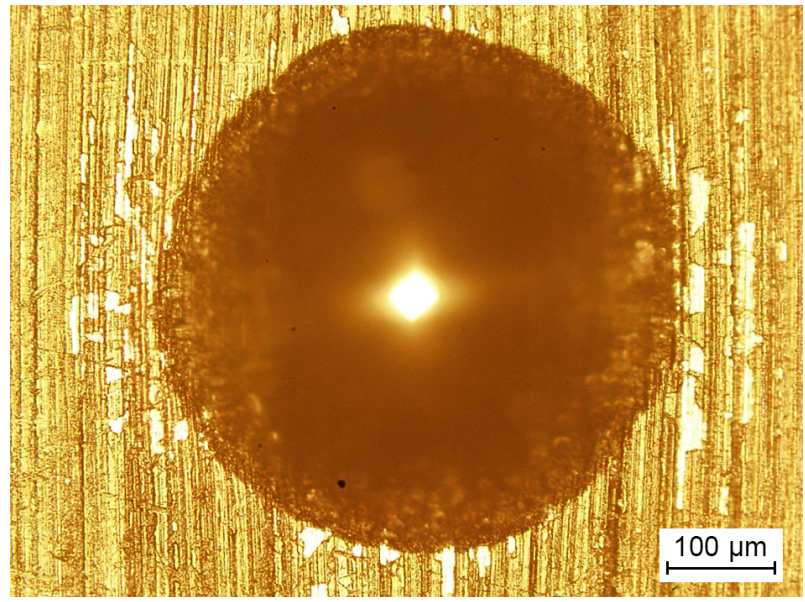
a) Coating TiCN (lower jaw)

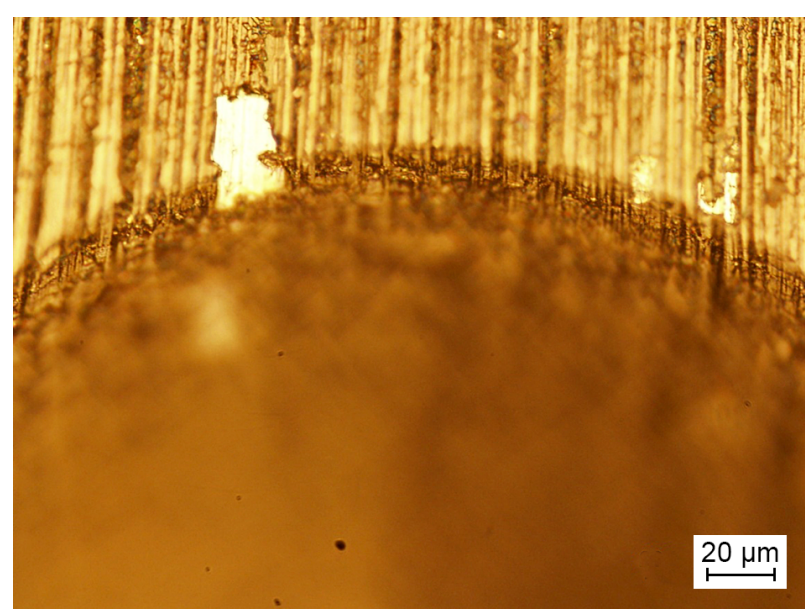

b) Detail of the impression in its top part

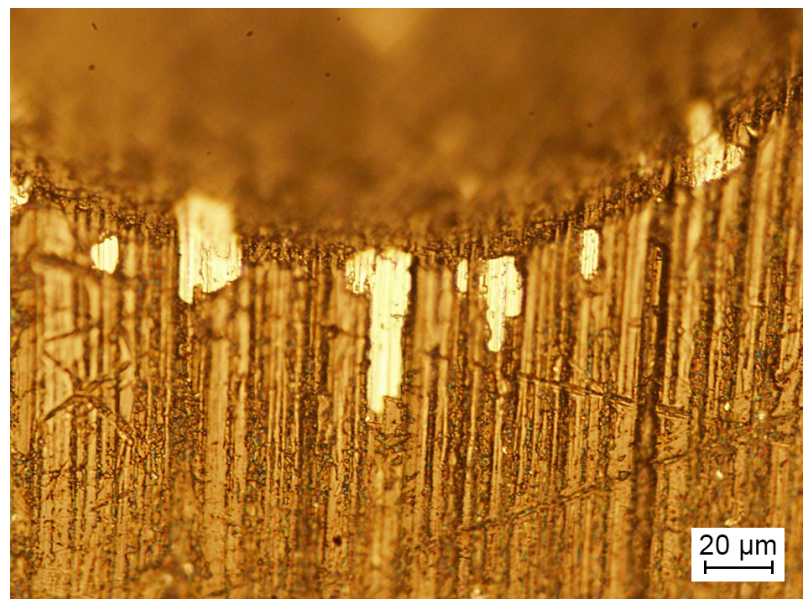

c) Detail of the impression in its lower part

Fig. 2. Characteristic of the adhesion of DLC coating deposited on EN 1.2379, X153CrMoV12 steel substrate, determined by Rockwell C test
The average microhardness values were as follows: $1196.8 \pm 84.9$ HV0.1 for TiCN coating; for DLC coating $1416.1 \pm 188.4$ HV0.1; for base material $360.9 \pm 26.87$. Based on the measured values, the PVD DLC coating showed higher hardness values.

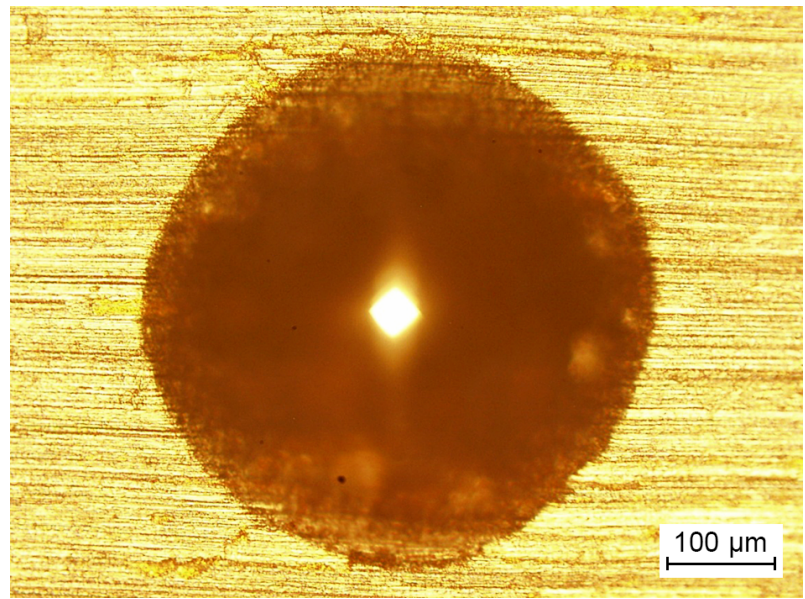

a) Coating TiCN (lower jaw)

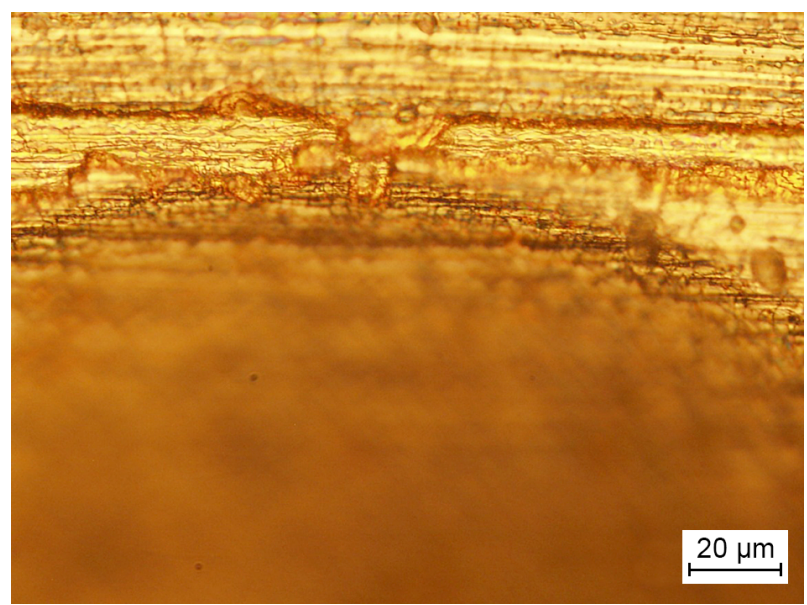

b) Detail of the impression in its top part

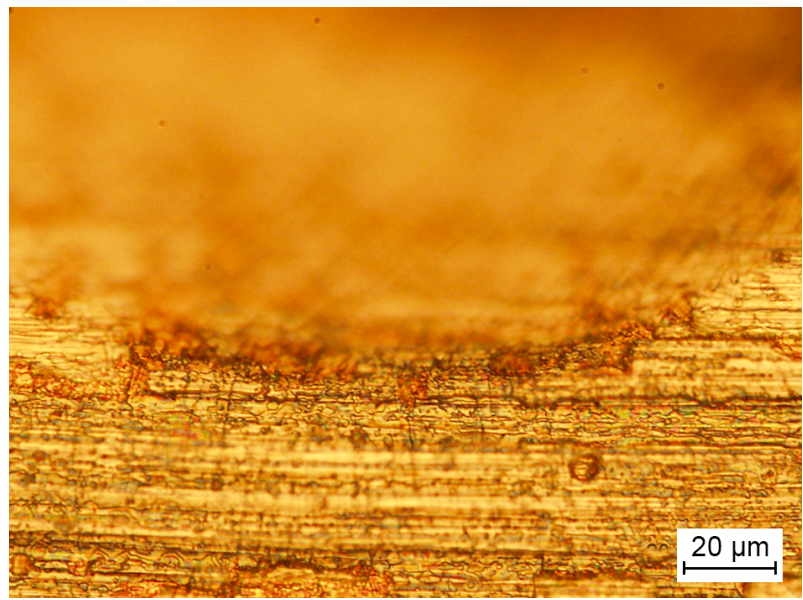

c) Detail of the impression in its lower part

Fig. 3. Characteristic of the adhesion of TiCN coating deposited on EN 1.2379, X153CrMoV12 steel substrate, determined by Rockwell $\mathrm{C}$ test 
A detailed view on the Rockwell impression of PVD DLC coating is documented in Fig. 2. Microscope images showed relatively small peeling of coating at the edges of the imprints, marked as HF2 degree, what can be explained by the amorphous nature of DLC coating. Similar results for DLC coatings were reported in [15].

The result of the Rockwell $\mathrm{C}$ adhesion test for multiple-layered TiCN coating, presented in Fig. 3, con- firmed a good adhesion of HF1 degree, without peeling. This can be attributed to its lower hardness, structure (toughness), higher thickness compared to the DLC layer.

Scratch test records and scratch tracks for the TiCN coating are shown in Figs. 4 and 5.

Scratch test records and scratch tracks for the DLC coating are shown in Figs. 6 and 7.

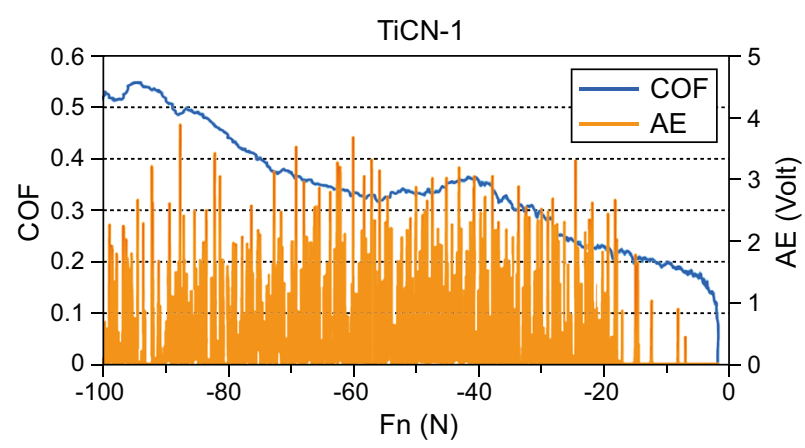

a)

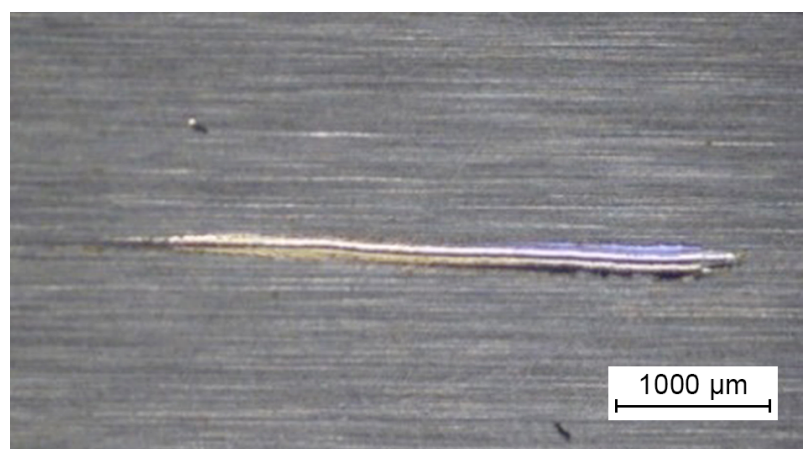

b)

Fig. 4. Scratch test: TiCN coated jaw - longitudinal direction: a) acoustic emission signal and COF versus normal force; b) scratch track on TiCN coating

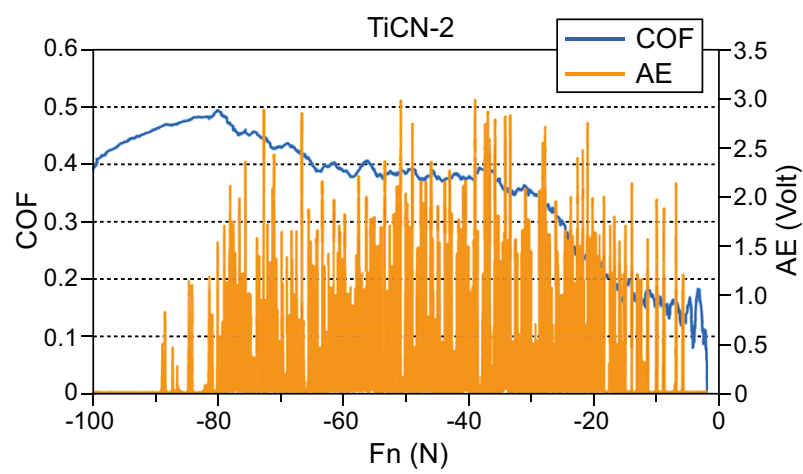

a)

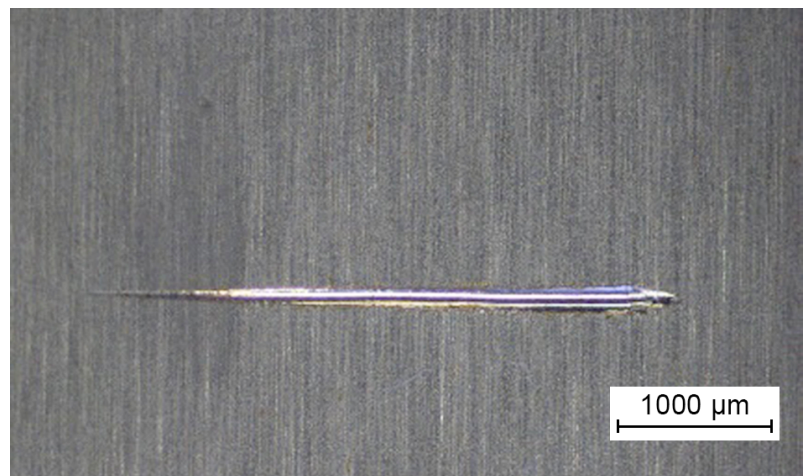

b)

Fig. 5. Scratch test: TiCN coated jaw - transverse direction: a) acoustic emission signal and COF versus normal force; b) scratch track on TiCN coating

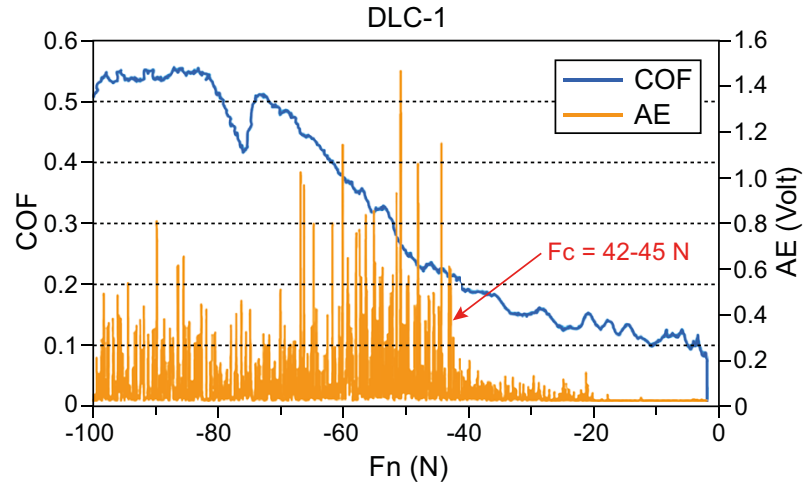

a)

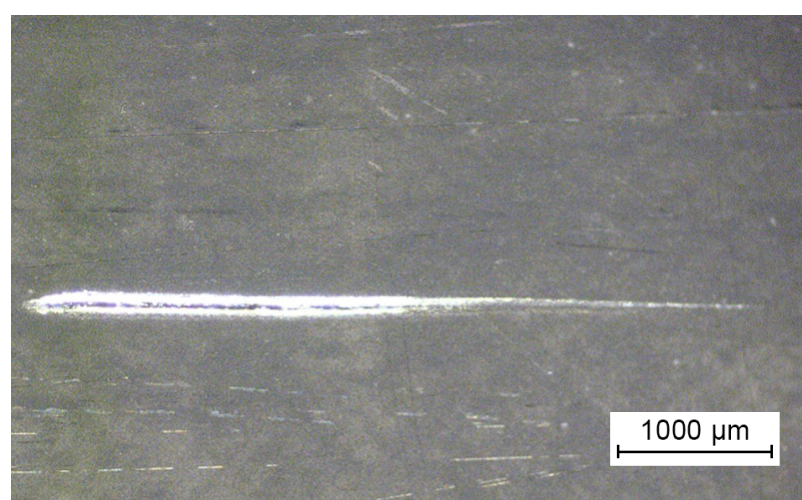

b)

Fig. 6. Scratch test: DLC coated jaw - longitudinal direction: a) acoustic emission signal and COF versus normal force; b) scratch track on DLC coating 


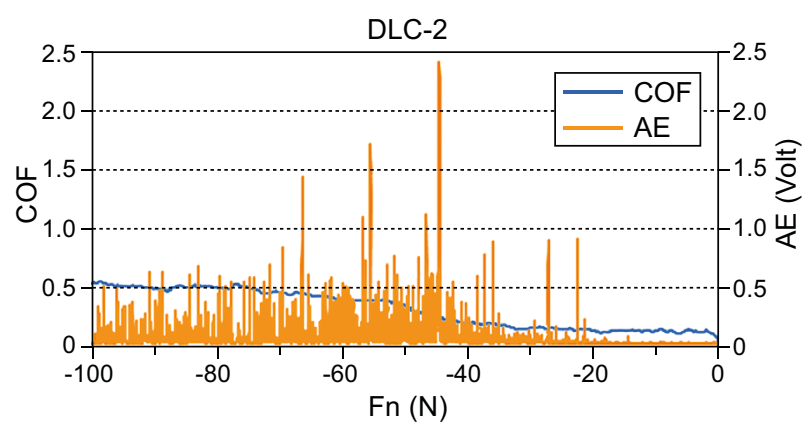

a)

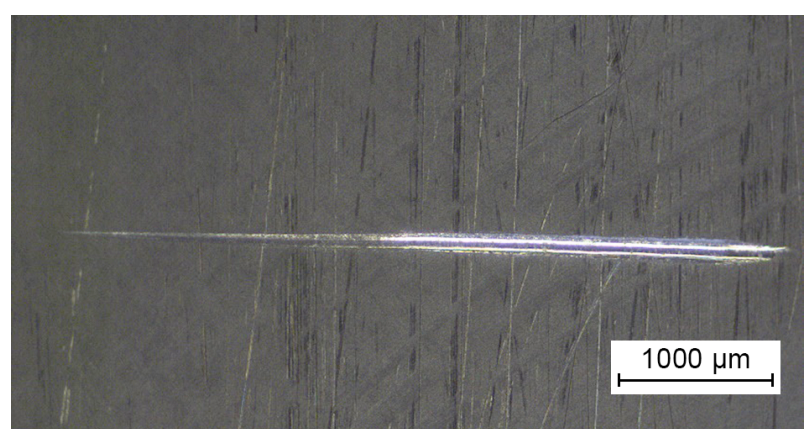

b)

Fig. 7. Scratch test: DLC coated jaw - transverse direction: a) acoustic emission signal and COF versus normal force b) scratch track on DLC coating

The critical force of coatings failure $F_{c}$ is recorded in Tab. 2

Tab. 2. Scratch test - critical force Fc at coating failure

\begin{tabular}{|l|c|c|}
\hline \multicolumn{3}{|c|}{ Adhesion of coating - scratch test } \\
\hline Direction of grinding: & PVD TiCN - jaw & PVD DLC - jaw \\
\hline longitudinal & $\mathrm{Fc} \approx 17 \mathrm{~N}$ & $\mathrm{Fc} \approx 42-45 \mathrm{~N}$ \\
\hline transverse & $\mathrm{Fc} \approx 5 \mathrm{~N}$ & $\mathrm{Fc} \approx 45 \mathrm{~N}$ \\
\hline
\end{tabular}

Based on evaluating the course of the acoustic emission dependence (AE) on normal force magnitude, it can be concluded that they are consistent with the morphology of the failure. For a harder DLC coating, failure in a brittle manner and a few spallations were observed during the scratch test. DLC coating presented high critical loads during the scratch test (42-45 N) compared to TiCN coating $(5 \mathrm{~N}$ for transverse a $17 \mathrm{~N}$ for longitudinal direction). Lower adhesion recorded for TiCN coating in the scratch test can indicate the impact of the preparation of the substrate and pre-treatment cleaning process. By comparing TiCN and DLC coatings deposited on ledeburitic high-alloyed $\mathrm{Cr}-\mathrm{Mo}-\mathrm{V}$ steel, the results of the scratch test showed a better adhesion of the DLC coating.

Problems with DLC coatings may occur due to residual stress problems, the higher levels of $\mathrm{sp}^{3}$ bonds lead to a harder coating but at the expense of higher pressure stresses (Morshed et al., 2003, Schwan, 1997). The internal pressure stresses in the DLC coatings can reach up to $10 \mathrm{GPa}$, which dramatically limits the coating thickness and such stresses may create unstable interfaces (e.g. the adhesion and/or cohesive problems) and the film may be susceptible to delamination [26].

Due to the better tribological properties of the DLC coating compared to the TiCN coating, the modified strip drawing test was carried out for DLC coated jaws. The calculated values of friction coefficients from the measured values of both drawing and blank holding forces according to equations (7) and (8) are given in Tab. 3.

Low friction coefficient values indicate good tribological properties of the DLC coating [6]. The view on the jaws coated with DLC coating after the modified friction test (blank holding force $8 \mathrm{kN}$ ) is shown in Figure 8. There no sticking of $\mathrm{Zn}$ coating on the jaws was observed, which corresponds with the low value of the coefficient of friction.

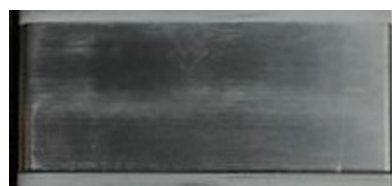

a) DLC coated upper jaw

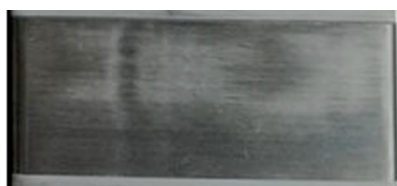

b) DLC coated lower jaw
Fig. 8. View on the functional part of jaws after friction test (dimensions of functional part of jaw: $20 \times 50 \mathrm{~mm}$ )

Tab. 3. Values of friction coefficient for DLC coating

\begin{tabular}{|l|c|c|c|c|}
\hline \multirow{2}{*}{$\begin{array}{l}\text { Characteristics } \\
\text { Lubricant Anticorit }\end{array}$} & \multicolumn{4}{|c|}{ Blank-holding force Fp [N] } \\
\cline { 2 - 6 } & $\mathbf{2 0 0 0}$ & $\mathbf{4 0 0 0}$ & $\mathbf{6 0 0 0}$ & $\mathbf{8 0 0 0}$ \\
\hline Measured drawing force $F_{t}[\mathrm{~N}]$ (unbraked roller) & 607 & 961 & 1268 & 1327 \\
\hline Friction coefficient $f_{2}$ calculated according to equation $(7)$ & - & 0.089 & 0.083 & 0.060 \\
\hline Measured drawing force $F_{t}[\mathrm{~N}]$ (braked roller) & 716 & 1124 & 1450 & 1555 \\
\hline Friction coefficient $f_{3}$ calculated according to equation $(8)$ & - & 0.090 & 0.067 & 0.097 \\
\hline
\end{tabular}

Note: Standard deviation were as follows: $F_{t} \pm 23 N, F_{p} \pm 50 N, f_{2}$ and $f_{3} \pm 0.003$ 
The DLC coating has confirmed its suitable tribological properties, but attention should be given to the preparation of the substrate. Calculated values of the friction coefficient for DLC coating between jaws and strip were in the range $0.089-0.060$ for applied pressures with decreasing tendency. The friction coefficient on the drawing edge varied from 0.097 to 0.067 , but dependence on blank holding force was not confirmed. It might be due to different specific pressure, which is higher on the drawing edge, as stated in [24], [27]. As reported in [28], the size of the contact area has a significant influence on the value of the friction coefficient, whereas the rigidity of the test stand is responsible for the qualitative course of the friction curve. It can be assumed that synergistic effect of prelube tribofilm, Zn coated steel and DCL coated jaws will be formed which can explains the low friction of $\mathrm{DLC} / \mathrm{Zn}$.

\section{CONCLUSIONS}

Nowadays, significant progress has been made in developing new materials and coatings that can provide exposed surfaces of stamping dies with improved tribological properties. The evaluation of coatings properties, such as thickness, hardness, and adhesion, was carried out by standard tests, and for selected coating, the friction coefficient was measured by the modified strip drawing test. Based on experimental works, we can state:

- The hardness of DLC coating (1416.1 \pm 188.4 HV0.1) with a thickness of $2.5 \mu \mathrm{m} \pm 0.5$ was about $18 \%$ higher compared to the hardness of TiCN coating $(1196.8 \pm 84.9 \mathrm{HV} 0.1)$ with a thickness of $3 \mu \mathrm{m} \pm 0.7$, both deposited on the tool steel with a hardness of $360.9 \pm 26.87$ HV0.1.

- Scratch test showed better adhesion of DLC coating compared to TiCN coating.

- Strip drawing test was carried out using a modified testing device with jaws and roller coated by DLC coating. Under lubricated conditions, the friction coefficient under the blank holder varied from 0.089 to 0.060 , depending on the blank holding force.

- Under lubricated conditions, the friction coefficient on the drawing edge varied from 0.097 to 0.067 , but dependence on the blank holding force was not confirmed.

- Synergistic effect of lubricant Anticorit Prelube 3802-39S, the DLC coated jaws, and Zn coated steel results in a lower friction coefficient.

Thin PVD coatings deposited on sheet metal stamping dies have the potential to optimize the stamping process and to increase the lifetime of the dies. The deposition of suitable self-lubricating coating on the stamping die may result in the forming process without the application of lubricant. The data obtained on the coatings, as well as the methods of evaluation of adhesion and friction coefficient, contribute to the assessment of the suitability of the surface-treated dies for the stamping processes or to make stamping dies more economical in use. The next research will focus on the study of the friction coefficient in the dry conditions.

\section{Acknowledgment}

This study was prepared with the support of projects VEGA 2/0080/192019 -2022, VEGA 1/0259/19, VEGA 2/0070/17, VEGA 1/0424/17, and NFP313010T594.

\section{REFERENCES}

1. P. Carlsson, M. Olsson: PVD coatings for sheet metal forming processes - a tribological evaluation. Surface and Coatings Technology 2006, 200, 4654-4663.

2. E. Zdravecká, M. Marton, A. Gmiterko, J. Tkáčová: Triboanalysis in Industry for PVD-coated Stamping Dies. Tribology in Industry 2014, 36 (1), 3-8.

3. K. Holmberg, A. Matthews: Coatings Tribology: Properties, Mechanisms, Techniques and Applications in Surface Engineering. Coatings Tribology 2009, 56, 576.

4. C. Donnet, A. Erdemir: Historical developments and new trends in tribological and solid lubricant coatings, Surface and Coatings Technology 2004, 180-181, 76-84.

5. K. Holmberg, H. Ronkainen, A. Matthews: Tribology of thin coatings. Ceramics International 2000, 26, 787-795.

6. S.V. Hainsworth, N.J. Uhure: Diamond like carbon coatings for tribology: production techniques, characterisation methods and applications. International Materials Reviews 2013, 52 (3), 153-174.

7. Ö.N. Cora, A. Ağcayazı, K. Namiki, H. Sofuoğlu, M. Koç: Die wear in stamping of advanced high strength steels - Investigations on the effects of substrate material and hard-coatings. Tribology International 2012, 52, 50-60.

8. PC. Siow, J.A. Ghani, M. Ghazali, T.R. Jaafar: Characterization of $\mathrm{TiCN}$ and $\mathrm{TiCN} / \mathrm{ZrN}$ coatings for cutting tool application. Ceramics International 2013, 39 (2), 1293-1298.

9. R. Lacombe: Adhesion Measurement Methods: Theory and Practice. Taylor and Francis, 2005.

10. R. Čada, M. Kijonka: Determination of friction coefficient at sheet-metal drawing. Acta Mechanica Slovaca 2006, 10 (2B), 85-90.

11. R. Čada, P. Tiller: Evaluation of draw beads influence on intricate shape stamping drawing process. Technological Engineering 2014, 9 (1), 5-10.

12. E. Evin, M. Tomáš, M. Výrostek: Benchmarking of friction models used in the simulation of deep drawing. Annals of Faculty Engineering Hunedoara - International Journal of Engineering 2012, 129-134.

13. E. Evin, S. Németh, M. Výrostek: Evaluation of Friction Coefficient of Stamping. Acta Mechanica Slovaca 2014, 18 (3-4), 20-27. 
14. H. Kim, S. Han, Q. Yan, T. Altan: Evaluation of Tool Materials, Coatings and Lubricants in Forming Galvanized Advanced High Strength Steels (AHSS). CIRP Ann. Manuf. Technol. 2008, 57, 299-304.

15. M. Pancielejko, A. Czyżniewski, V. Zavaleyev, A. Pander, K. Wojtalik: Optimization of the deposition parameters of DLC coatings with the MCVA method. Archives of Materials Science and Engineering 2012, 52 (4), 60-67.

16. A. Erdemir, Ch. Donnet: Tribology of diamond-like carbon films: recent progress and future prospects. J. Phys. D: Appl. Phys. 2006, 39, R311-R327.

17. H. Kim, S. Han, Q. Yan, T. Altan: Evaluation of tool materials, coatings and lubricants in forming galvanized advanced high strength steels (AHSS). CIRP Annals Manufacturing Technology 572008 p. 299-304.

18. B. Sresomroeng, V.Premanond,P.Kaewtatip,A.Khantachawana, N. Koga, S. Watanabe: Anti-adhesion performance of various nitride and DLC films against high strength steel in metal forming operation. Diamond and Related Materials 2010, 19, 833-836.

19. W.J. Shen, M.H. Tsai, J.W. Yeh: Machining Performance of Sputter-Deposited $\left(\mathrm{Al}_{0.34} \mathrm{Cr}_{0.22} \mathrm{Nb}_{0.11} \mathrm{Si}_{0.11} \mathrm{Ti}_{0.22}\right)_{50} \mathrm{~N}_{50}$ HighEntropy Nitride Coatings. Coatings 2015, 5 (3), 312-325.

20. ANTICORIT PL 380239 S. Industrial and Automotive Lubricants. Fuchs Schmierstoffe GmbH. https://www. fuchs.com/de/en. (accessed 10 Dec 2019)
21. D. Jakubéczyová, M. Hagarová, I. Štěpánek: Evaluation of thin PVD coatings by adhesive-cohesive test. Annals of Faculty Engineering Hunedoara - International Journal of Engineering 2011, 9 (1), 79-82.

22. M. Hagarová, D. Jakubéczyová, G. Baranová, M. Eliáš: Adhesion determination of thin wear resistant coatings. Materials Science Forum 2019, 952, 107-113.

23. E. Zdravecká, V.M. Tiainen, Y.T. Konttinen, L. Franta, M. Vojs, M. Marton, M. Ondáč, J. Tkáčová: Relationships between the fretting wear behavior and mechanical properties of thin carbon films. Vacuum 2012, 86 (6), 675-680.

24. E. Evin, M. Tomáš, M. Výrostek: Verification the Numerical Simulation of the Strip Drawing Test by its Physical Model. Acta Mechanica Slovaca 2016, 20 (1), 14-21.

25. E. Evin, M. Tomáš, M. Kollárová, B. Antoszewski: Some tribological aspects of $\mathrm{Fe}-\mathrm{Zn}$ coated steel sheets at stamping processes. Acta Metallurgica Slovaca 2014, 20 (2), 189-199.

26. PA. Dearnley, A. Neville, S. Turner, H. Scheibe, R. Tietema, R. Tap, et al.: Coatings tribology drivers for high density plasma technologies. Surface Engineering 2010, 26.

27. A. Losch: Sheet Metal Forming Lubricants. In: Mang T. (eds) Encyclopedia of Lubricants and Lubrication. Springer: Berlin, 2014.

28. V. Recklin, F. Dietrich, P. Groche: Influence of Test Stand and Contact Size Sensitivity on the Friction Coefficient in Sheet Metal Forming. Lubricants 2018, 41 (6), 13. 